\title{
Grouting mortar for annular injection
}

\author{
Olga Lyapidevskaya ${ }^{1, *}$ \\ ${ }^{1}$ Moscow State University of Civil Engineering, Yaroslavskoe shosse, 26, Moscow, 129337, Russia
}

\begin{abstract}
In conditions of cramped urban development, trenchless methods of laying engineering communications are used for environmental protection. Currently, the most widespread is shield driving with tunneling complexes. However, during construction work voids and crevices may form between the shell of the shield and the tunnel lining. In order to fill these voids and create a durable waterproof screen around the lining, the technology of injecting grouting mortars in the annular space is applied. The article shows the results of laboratory tests and gives a comparative analysis of applied grouting mortars based on mineral binders. A new composition of a grouting mortar with improved characteristics including Portland cement and bentonite clays is proposed. The results of laboratory tests of a new material are presented. Data are given that indicate the advantages of using bentonite powders for the preparation of grouting compositions over other materials used as protective injection mortars. The article contains information about field tests of the developed material, which show that the proposed grouting mortar is characterized by high rheological properties and allows obtaining a high-quality waterproof shell in the annulus.
\end{abstract}

\section{Introduction}

Currently, there is an active development of urban underground space. This process is especially rapid in megacities. This is primarily due to the increasing pace of town planning, the erection of both new buildings and structures, as well as the reconstruction of existing buildings. For the normal functioning of industrial and civil facilities, it is necessary to create a developed underground infrastructure that meets modern requirements. Up-to-date construction technologies require more innovative solutions for laying underground communications and ensuring their uninterrupted operation, both in the new and in the conditions of the already existing development [1].

When laying pipeline communications, trench and trenchless methods are used. The trench method provides for a large amount of excavation work to create a ditch, digging soil, etc., which leads to a violation of the fertile layer and the elimination of green spaces. In addition, trenching works have a high cost and duration of assembly operations. In order to ensure the geoecological safety of the urban environment and the preservation of the existing infrastructure, methods of trenchless laying of underground communications are used. Trenchless laying does not require the opening of the soil, has a high speed of installation, and demands less material costs. Trenchless pipe laying technologies provide

\footnotetext{
* Corresponding author: olga.lyapidevskaya@inbox.ru
} 
through passage through soil layers, which eliminates the possibility of subsidence and helps to preserve the environment. In the cramped conditions of urban development, the most common is the shield laying of pipes by tunneling complexes. The mechanized tunnel shield is a movable prefabricated metal structure in the form of a hollow cylinder, including a body (temporary mobile mechanized support), mechanisms for the development and loading of rock into the face and moving it outside the shield. The shield consists of three main parts: cutting head (in which the process of drilling and mining of the rock takes place), body (for placing auxiliary equipment and hydraulic jacks that force the shield to move forward) and tail (to ensure the protection of personnel in the construction of a permanent support) (Figure1) [2, 3].

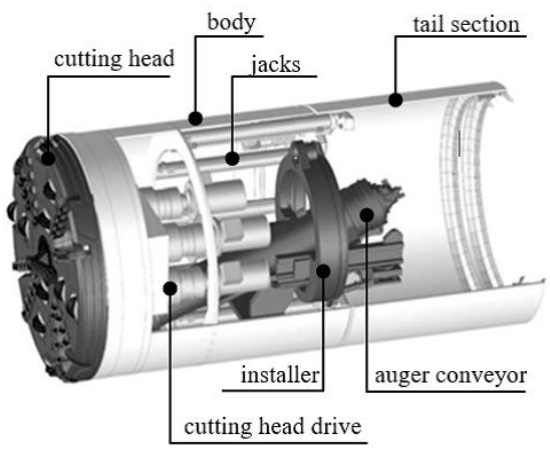

Fig. 1. Mechanized tunnel shield

\section{Methods - Grouting mortars for injection}

During the construction work between the shield shell and the lining of the tunnel, voids and gaps are formed. To fill these voids and create a reliable waterproof screen around the lining, the injection of special (grouting) mortars in the annular space of the tunnel is carried out. The hardened mortars provide joint work of the lining with the surrounding soil. The grouting mortar is pumped through the holes in the block of the tunnel structure in the radial direction. The use of this technology allows reducing the deformation of the lining, improving water resistance, corrosion resistance and durability of structures [4-7].

For the implementation of injection works, cement-sand mortars with mineral and polymeric additives are used. To replace a part of cement, it is possible to use mineral finedispersed aggregates: fly ash, clay or clay powders, bentonite clays, microsilica, etc .; it is also possible to use a mixture of a multicomponent cement-free binder, aggregate, water and additives [8-12]. To ensure easy pumping of mortar mixes and quality filling of the gap between the lining and the ground, the mortar mixtures must have high flowability and do not segregate; the setting time should ensure the full filling of the construction gap before the initial set and prevent the sticking of the mortar on the shield shell; and the hardened mortar (grouting stone) has a high water resistance and sufficient strength in the early periods and 28-day age. Fine-dispersed and chemical additives in the form of separate components or their combinations are introduced into mortars to reduce the consumption of cement, improve the technological properties of the grouting mortar (flowability, prevent segregation, etc.), regulate the setting time, increase the density and water permeability of the grouting stone $[13,14]$.

Requirements to the rheological and physical-mechanical properties of cement-based and cement-free grouting mortars are given in the Table $1[1,3]$. 
Table 1. Requirements for cement-based and cement-free grouting mortars

\begin{tabular}{|l|c|c|}
\hline \multirow{2}{*}{ Parameter } & \multicolumn{2}{c|}{ Standard value for grouting mortars } \\
\cline { 2 - 3 } & cement-based & cement-free \\
\hline Flowability, cm & $10-30$ & $15-20$ \\
\hline Segregation, cm, less than & 5 & 2 \\
\hline Water gain within 1 $\mathrm{h}, \%$, not more than & 2 & 2 \\
\hline Output of the grouting stone, $\%$, not less than & $95-100$ & $95-100$ \\
\hline Density of the grouting stone, $\mathrm{kg} / \mathrm{m}^{3}$, not less than & 1500 & 1500 \\
\hline Filtration coefficient of the grouting stone, $\mathrm{cm} / \mathrm{s}$, not more than & $1 \times 10^{-7}$ & $1 \times 10^{-7}$ \\
\hline $\begin{array}{l}\text { Compressive strength of the grouting stone at the age of } 28 \\
\text { days, MPa, not less than }\end{array}$ & 5,0 & 1,5 \\
\hline
\end{tabular}

\section{Experiment}

We have made an attempt to develop a reliable waterproofing of the annular space by applying a new effective grouting mortar with improved properties in comparison with the traditionally applied ones.

When developing the composition of the injection mortar, the requirements dictated by both the injection technology and the further work of the material in the annular space were taken into account (Table 1). Based on these conditions, the mortar must have a high flowability and maintain pumpability for at least 24 hours, as in accordance with the drilling technology, the mortar can remain in the pump hopper and hoses for more than 12 hours and should not create plugs in the equipment system. The mortar should not flake, be homogeneous and have a fixed water gain (up to $2 \%$ ). At the same time, at a pressure of 1 bar, created behind the lining during pumping, the mortar must give off excess water and form a dense, non-shrinkable structure having initial strength, and thereby maintain the lining in the design position and prevent its possible movements.

For laboratory tests, the base grouting mortars were selected $[15,16]$ :

- composition No. 1 - hydraulic lime, microsilica, fly ash, quartz sand, water (Table 2);

- composition No. 2 - Portland cement, fly ash, quartz sand, superplasticizer, sodium fluoride, water (Table 3).

Table 2. Composition of the grouting mortar No. 1

\begin{tabular}{|l|c|}
\hline \multicolumn{1}{|c|}{ Component } & Content, $\mathrm{kg} / \mathrm{m}^{3}$ \\
\hline Hydraulic lime & 90 \\
\hline Microsilica & 30 \\
\hline Fly ash & 300 \\
\hline Fine aggregate (quartz sand) & 1360 \\
\hline Water & 360 \\
\hline
\end{tabular}

Table 3. Composition of the grouting mortar No. 2

\begin{tabular}{|l|c|}
\hline \multicolumn{1}{|c|}{ Component } & Content, $\mathrm{kg} / \mathrm{m}^{3}$ \\
\hline Portland cement & 415 \\
\hline Fly ash & 415 \\
\hline Fine aggregate (quartz sand) & 830 \\
\hline Superplasticizer C-3 & 2,1 \\
\hline Sodium fluoride & 12,4 \\
\hline Water & 330 \\
\hline
\end{tabular}


To improve the flowability and waterproofing properties of the grouting mortar, the composition No. 3 was proposed:

- Portland cement, bentonite powder, fine aggregate (quartz sand), additives-regulators of properties: potassium carbonate, plasticizer, polyacrylamide (Table 4).

When selecting the components of the composition, the requirements determined by the injection technology and the subsequent work of the material behind the lining were taken into account.

Table 4. Composition of the grouting mortar No. 3

\begin{tabular}{|l|c|}
\hline \multicolumn{1}{|c|}{ Component } & Content, $\mathrm{kg} / \mathrm{m}^{3}$ \\
\hline Portland cement & 623 \\
\hline Bentonite powder & 324 \\
\hline Fine aggregate (quartz sand) & 581 \\
\hline Potassium carbonate & 20,5 \\
\hline Plasticizer & 4,87 \\
\hline Polyacrylamide & 2,26 \\
\hline Water & 486 \\
\hline
\end{tabular}

As a binder, we used Portland cement without mineral additives - class CEM I $42.5 \mathrm{~N}$ [17]. Manufacturer - JSC "Holcim" (Rus) CM" Kolomna, Moscow region.

In order to reduce the water loss of the grouting mortar, increase fluidity and penetrability, that should be maintained during the injection time into the pluggable cavities, bentonite clay powder was used. Bentonite is a natural clay mineral, which contains at least $70 \%$ of montmorillonite, which can swell by 14-16 times when hydrated. At the same time, a dense gel forms, that prevents penetration of moisture. This property of bentonite powders allows them to be successfully used to reduce filtration and promote gelling of mortars used in the drilling and tunnel driving. The consumption of bentonite powder in the composition of a grouting mortar was determined in accordance with the following peculiarities of bentonite clays: in case of a lack of bentonite, pumping of a grouting mortar will be difficult, and with its excess the binding properties of the mortar will be decreased which will increase the water permeability of the stone [18].

Table 5 shows the main characteristics of the bentonite powder selected for the study. Manufacturer - LLC "Bentoprom", Stary Oskol, Belgorod region [19].

Table 5. Characteristics of bentonite powder

\begin{tabular}{|l|c|}
\hline \multicolumn{1}{|c|}{ Parameter } & Bentonite powder \\
\hline Yield of the clay mud, more than, $\mathrm{m}^{3} / \mathrm{t}$ & 16 \\
\hline Viscosity, more than & 36 \\
\hline Water loss, $\mathrm{cm}^{3}$, less than & 14 \\
\hline Montmorillonite consumption, \%, more than & 80 \\
\hline Fineness of grinding (sieve residue No. 0074), \%, less than & 2,5 \\
\hline Humidity of raw materials, \%, less than & 10 \\
\hline
\end{tabular}

Quartz sand with the fineness modulus $\mathrm{Mk}=1.5$ was used as a fine aggregate. Producer - LLC "Litvinovsky Quarry", Solnechnogorsk district, Moscow region. To improve the flowability and non-segregation of the mortar, as well as to increase the output of the grouting stone, polycarboxylate SikaPlast ${ }^{\circ}-1$ BetonPlast was used as a plasticizer. Producer - LLC "Sika", Lobnya, Moscow Region. In order to regulate the increase in the volume of clays during hydration, an inhibitor of clay swelling - polyacrylamide (PAA) Polyflok was used. This is a water-soluble powder of white color with particle size not exceeding $1.4 \mathrm{~mm}$, density $1150-1200 \mathrm{~kg} / \mathrm{m}^{3}$, bulk density $-600-800 \mathrm{~kg} / \mathrm{m}^{3}$ [20]. Potash 
(potassium carbonate) was used to accelerate hardening and prevent freezing of grouting mortars in winter.

\section{Results of the study of physical and mechanical properties}

Laboratory studies of the presented compositions were carried out in accordance with the current standards [21]. Table 6 presents the results of physical and mechanical tests of grouting mortars No.1 - No. 3.

Table 6. Results of physical and mechanical tests of grouting mortars

\begin{tabular}{|l|c|c|c|}
\hline \multirow{2}{*}{ Parameter } & \multicolumn{3}{c|}{ Laboratory compositions of the grouting } \\
\cline { 2 - 4 } & No. 1 & No. 2 & No. 3 \\
\cline { 2 - 4 } & 13 & 12 & 22 \\
\hline Flowability, cm & 5 & 4 & 1 \\
\hline Segregation, $\mathrm{cm}$, & 2 & 2 & 1 \\
\hline Water gain within 1 $\mathrm{h}, \%$ & 95 & 96 & 98 \\
\hline Output of the grouting stone, \% & 1860 & 1750 & 1700 \\
\hline Density of the grouting stone, $\mathrm{kg} / \mathrm{m}^{3}$ & $1,0 \times 10^{-7}$ & $8,5 \times 10^{-8}$ & $1,5 \times 10^{-8}$ \\
\hline Filtration coefficient of the grouting stone, $\mathrm{cm} / \mathrm{s}$ & 0,2 & 1,0 & 0,8 \\
\hline $\begin{array}{l}\text { Compressive strength of the grouting stone at the age of } \\
\text { 1 day, MPa }\end{array}$ & 2,0 & 20,0 & 12,0 \\
\hline $\begin{array}{l}\text { Compressive strength of the grouting stone at the age of } \\
\text { 28 days, MPa }\end{array}$ & & & \\
\hline
\end{tabular}

As follows from the presented data on the results of testing samples of the grouting mortars, the developed grouting mortar (No. 3) has high rheological properties in comparison with the compositions No. 1 and No. 2 and increased mechanical characteristics as compared to the composition No. 1.

\section{Conclusion}

The implementation of the developed grouting mortar was carried out during the construction of the cable collector of the Novo-Kuzminki electrical substation, by the method of shield driving. The mortar was injected into the annular space to create a groundwater cutoff and stability of the mine working. Full-scale tests showed that the applied grouting mortar was characterized by high rheological properties and allowed obtaining a quality waterproof shell in the annular space. At the same time, a high shield driving speed was achieved in the absence of defects in the blocks of the tunnel lining.

\section{References}

1. VSN 132-92, Rules of production and acceptance of grouting work for the tunnel lining (ZNIIS, 1992)

2. D. Peila, L. Borio, S. Pelizza, Acta geotechnica slovenica, 1, 5-15 (2011)

3. STO NOSTROY 2.27.19-2011, Development of underground space. Tunnelling with Tunnel boring machines (TBMs), using precast concrete segments (PC segments) (2011)

4. R. Vinai, C. Oggeri, D. Peila. Tunnelling and Underground Space Technology, 23(3), 308-317 (2007)

5. S.-D. Hwang, K. H. Khayat, R. Morin, Canadian Journal of Civil Engineering, 38(4), 422-432 (2011) 
6. J. J. Assaad, Y. Daou, Cement and Concrete Research, 59, 43-54 (2014)

7. M. J. Shannag, Cement and Concrete Research, 32(5), 803-808 (2002)

8. A. Gurdzhiev, Drilling and oil, 3, 36-37 (2007)

9. G.N. Lyshko, Drilling and oil, 9, 50 (2013)

10. N.A. Mikulshin, Cement and its application, 5, 64-66 (2013)

11. Yu.A. Nifontov, Z.Z. Sharafutdinov, T.I. Nifontova, Oil. Gas. Innovations, 11, 53-55 (2014)

12. L.I. Riabova, Oil industry, 4, 60-63 (2010)

13. C. Ma, Y. Tan, E. Li, Y. Dai, M. Yang, Advances in Materials Science and Engineering, 2015, 1-11 (2015)

14. I. N. Markou, A. I. Droudakis, Geotechnical and Geological Engineering, 31(4), 10411058 (2013)

15. A.K. Sherstnev, O.B. Lyapidevskaya, Scientific review, 10-2, 39-43 (2015)

16. D. Lesueur, C. Joly, D.Puiatti, F. Verhelst, J. Burdin, Tunnels et espace souterrain, 235, 35-42 (2013)

17. GOST 31108-2016, Common cements. Specifications (2016)

18. TU 4191-001-58156178-02, Molding bentonite powder clays (2002)

19. TU 5751-002-58156178-02, Mud powders for borings (2002)

20. TU 2414-002-74301823-2007, Polymers of acrylamide. Polyflok (2007)

21. GOST 5802-86 Mortars. Test methods (1986) 